\title{
Subjective determinants of social activity of the student youth
}

\author{
Irina Arendachuk* \\ Faculty of Psychological and Pedagogical and Special Needs Education, Saratov State \\ University, 410012 Saratov, Russia
}

\begin{abstract}
The article contains the analysis of peculiarities of social activity of students at different levels of professional education, aimed at the identification of typical spheres of its manifestation and subjective determinants. The sample contained 138 college and university students aged from 17 to 25 (Saratov Region, Russia). The questionnaire helped to explore forms of social activity and related spheres of life. In order to study subjective characteristics we used: the questionnaire for studying the structure of subjectivity (E. N. Volkova, I. A. Seregina), "Level of personal subjectivity development" technique (M. A. Shchukina), personality selfdetermination test (B. Sheldon, modified by E. N. Osin). It has been shown that the most typical spheres of social activity manifestation among the student youth are leisure, virtual, and educational spheres of life. College students' subjective determination of social activity was not revealed; its predictors among bachelor's students are level characteristics of subjectivity development "mediation-immediacy" and personality's selfdetermination markers "autonomy" and "self-expression", while level characteristics among master's students are "creativity-mediocrity", "autonomy-dependency", "integrity-non-integrability", and "selfdevelopment". The higher the level of professional education received by students, the less pronounced is their social activity, which is becoming more and more determined by personal subjective characteristics.
\end{abstract}

\section{Introduction}

The relevance of studies of different aspects of the student youth activity within social context is determined by its special position in the society. Russian researchers point out the contradictory status of this socio-psychological group, and simultaneously characterize its social immaturity, political indifference, and social innovativeness as the source of social transformation [1]. On the one hand, students do not see the opportunity for manifestation of their social activity and therefore realize it through communication and the establishment of social contacts to achieve their self-realization goals [2], on the other hand they try to influence the world and people around them and express their individuality [3]. Foreign researchers emphasize the progressive potential of modern youths and see them as the carriers of social development capable of leading the society out of crisis (crisis of values, economy, and civilization in general) [4], focus on their desire to participate in social life,

\footnotetext{
* Corresponding author: arend-irina@yandex.ru
} 
to search for the new social connections [5]. During the acquisition of professional education young people want to not only find their own place within the system of social relations but also to choose their professional future, thus striving for deep assimilation and practical application of knowledge and scientific and creative abilities for the benefit of society and themselves [6,7]. The specifics of student youths social activity is also determined by the search for the possibilities of meeting new friends, communicating with the professionals in their chosen area, and finding new hobbies, which could be helpful in determining their personal and professional growth [8].

Viewing social activity as conscious, purposeful interaction between an individual and society, it should be noted that particular forms of its manifestation among student youths is determined not only by the peculiarities of their educational and professional activities but also by the specifics of the social groups in which they are included during the process of receiving professional education. In these groups a student's personality not only determines itself, but also shows its subjective qualities which reflect its position towards the surrounding reality. Hence there is the need to search for the answer to the question which exactly subjective qualities determine certain forms of its social activity. This is what the present study is dedicated to; the results of the study are presented in this article.

\section{Materials and Methods}

The sample consisted of 138 students (Saratov Region, Russia) receiving vocational education $(\mathrm{n}=48)$ and higher education (Bachelor's Degree, $\mathrm{n}=42$ and Master's Degree, $\mathrm{n}$ $=48$ ), aged 17 to $25,41,3 \%$ of which were male and $58,7 \%$ - female.

Students' social activity was defined using the questionnaire containing 12 forms of social activity, which were assessed by the participants according to the level of their manifestation on the scale from 1 ( $\mathrm{min}$ ) to 5 ( $\max$ ) (R.M. Shamionov, I.V. Arendachuk, E.E. Bocharova, and others). Each of these forms of social activity (altruistic, leisure, sociopolitical, Internet-network, civil, socio-economic, educational, spiritual, religious, protest, radical protest, subcultural) were thoroughly revealed in the questionnaire through the types of activity realized in them and related spheres of life [9]. For the study of students' subjective characteristics were used: a questionnaire for studying the structure of subjectivity by E. N. Volkova and I. A. Seregina (conscious activity; reflection ability; freedom of choice and responsibility for it; realization of one's own uniqueness; understanding and acceptance of others; self-development) [10], the technique called 'The level of personal subjectivity development' by M. A. Shchukina (activity-reactivity, autonomy-dependency, integrity-non-integrability, mediation-immediacy, creativity mediocrity, self-worthiness - worthlessness) [11], and personality self-determination test by B. Sheldon, modified by E. N. Osin (autonomy and self-expression) [12].

The sample was checked for normal distribution according to the Pearson's chi-squared test $\left(\chi^{2}\right)$. Comparative analysis using Student's t-test showed considerable discrepancies in the level of prominence of the types of social activity in the groups of students of different level of professional education (vocational education and higher education - Bachelor's and Master's Degrees); its influence on the prominence of the indicators under study was analysed according to the Kruskal-Wallis H-test. The predictors of social activity in student groups were determined in the process of multiple regression analysis (step-by-step inclusion of variables in regression model method).

\section{Results and Discussion}


The sample's check for normal distribution was done using the overall index of prominence of social activity which shows the average value of student's assessment of their activity in all its forms presented in the questionnaire. The value of Pearson's chi-squared test $\chi^{2}=$ 9,83 was smaller than the calculated critical $(7,01$ at $\mathrm{df}=9)$, and its confidence level $\mathrm{p}=$ 0,36 was higher than $p=0,05$, which testified to the statistical insignificance of these indicators and the compliance of the sample with the normal distribution.

Comparative analysis showed the greatest prominence of leisure, online, and educational activities of the student youths regardless of the level of education they were receiving. Besides, bachelor's students also have a high level of spiritual activity associated with the introduction to cultural heritage of the society. College and bachelor's students are more active in terms of altruistic, gratuitous, socially useful activity, as well as civil activity aimed at transformation of the society. Despite the small level of prominence of the types of activity connected with the opposition to public standards and requirements (protest, radical protest, and subcultural), they are more prominent among college students and almost absent among bachelor's and master's students. The same tendency is observed in relation to religious activity - it is prominent at maximum among college students, slightly lower among bachelor's students, and is insignificant for master's students. The level of received education has no effect on the student's manifestation of socio-political and socioeconomic activities - according to the data their manifestations are situational in nature (table 1).

Table 1. The parameters of student youths' involvement in different forms of social activity

\begin{tabular}{|l|c|c|c|l|l|l|l|}
\hline \multirow{2}{*}{$\begin{array}{c}\text { Forms of social } \\
\text { activity }\end{array}$} & \multicolumn{3}{|c|}{ Level of education } & \multicolumn{2}{c|}{$\begin{array}{c}\text { Group comparison according to the } \\
\text { level of education, } \mathrm{tst}\end{array}$} & \multirow{2}{*}{ H } \\
\cline { 2 - 7 } & College & BA & MA & College/BA & BA/MA & College/MA & \\
\hline Altruistic & 2,80 & 2,98 & 2,42 & $-0,88$ & $2,67^{* *}$ & 1,93 & $7,46^{*}$ \\
\hline Leisure & 3,26 & 3,72 & 3,55 & $-2,51^{* *}$ & 1,15 & $-1,91$ & $7,91^{*}$ \\
\hline Socio-political & 2,44 & 2,47 & 2,27 & $-0,16$ & 1,03 & 0,95 & 0,98 \\
\hline Internet-network & 2,96 & 3,33 & 3,34 & $-1,83$ & $-0,08$ & $-2,01^{* *}$ & 5,41 \\
\hline Civil & 2,67 & 2,68 & 2,00 & $-0,03$ & $3,37^{* *}$ & $3,52^{* *}$ & $13,52^{* *}$ \\
\hline Socio-economic & 2,70 & 2,91 & 2,80 & $-1,00$ & 0,47 & $-0,48$ & 1,06 \\
\hline Educational & 2,88 & 3,42 & 3,43 & $-2,62^{* *}$ & $-0,01$ & $-3,04^{* *}$ & $8,79^{*}$ \\
\hline Spiritual & 2,52 & 3,18 & 2,54 & $-2,98^{* *}$ & $2,77^{* *}$ & $-0,09$ & $11,11^{*}$ \\
\hline Religious & 2,38 & 2,03 & 1,65 & 1,44 & 1,74 & $3,67^{* *}$ & $9,91^{*}$ \\
\hline Protest & 2,05 & 1,40 & 1,13 & $3,51^{* *}$ & $2,64^{* *}$ & $6,23^{* *}$ & $24,90^{* *}$ \\
\hline Radical protest & 1,97 & 1,31 & 1,25 & $3,69^{* *}$ & 0,50 & $4,28^{* *}$ & $23,24^{* *}$ \\
\hline Subcultural & 2,17 & 1,84 & 1,11 & 1,54 & $4,87^{* *}$ & $7,01^{* *}$ & $30,35^{* *}$ \\
\hline $\begin{array}{l}\text { Social(overall } \\
\text { index) }\end{array}$ & 2,57 & 2,61 & 2,29 & $-0,28$ & $2,94^{*}$ & $2,30^{*}$ & $10,32^{*}$ \\
\hline
\end{tabular}

Note. Accepted designations: College - vocational education; BA - higher education (Bachelor's Degree); MA - higher education (Master's Degree); tst - Student's t-test; H - Kruskal-Wallis Htest's statistics. The levels of importance of the differences found are marked as follows: ${ }^{*}-\mathrm{p}<$ 0,$05 ;{ }^{*}-\mathrm{p}<0,001$.

The obtained data conforms with the results presented by us earlier in the study of manifestations of youths' social activity within the dynamics of age development [13] and means that student youths' social activity is dominant in leisure, virtual, and educational spheres of life. The higher the level of received education is, the more prominent are forms of activity connected with the realization of leisure activity, with the satisfaction of their interest on the Internet and through educational activities. Generally, student youths' social activity has a tendency to decline when receiving professional education of the higher level - its prominence among the master's students is significantly lower in comparison to college and bachelor's students. 
The regression analysis performed in order to identify the determination of social activity by the subjective characteristics of personality did not reveal any significant predictors among the students receiving vocational education in colleges. This result allows to assume that college students manifest their activity in different spheres of social life through the realization of objective behavioral strategies - either focusing on the group interests, assessments, and opinions, or on the impulsive satisfaction of their interests and needs without consideration of other people's peculiarities and overall situation. Bachelor's students showed the following predictors of social activity as subjective: the level characteristics of subjectivity development "mediation-immediacy" and self-determination of personality characteristics "autonomy" and "self-expression". Regression model for this group of students describes $37,5 \%$ of the variation of the dependent variable (social activity) and adequately reflects its determination by the accentuated factors: their coefficients turned out to be significant at the level of 0,01 ; F-test testifies for the general significance of the regression equation; the standard-error of the equation $(0,052)$ is no more than 5\% (2\%). Predictors of social activity among master's students were the level characteristics of subjectivity development "creativity-mediocrity", "autonomydependency", "integrity-non-integrability", and also personality subjective characteristic "self-development". The given model describing 57,3\% of the variation of the dependent variable is also effective for describing master's students' social activity determination: the accentuated predictors are significant at the level of 0,01 ; F-test testifies to the general significance of the regression equation, its standard-error $(0,025)$ is $1,1 \%$ (within no more than 5\%) (table 2).

Table 2. Regression model of social activity's determination by subjective characteristics among the youths receiving higher education

\begin{tabular}{|c|c|c|c|c|c|}
\hline $\begin{array}{c}\text { The model's } \\
\text { structural components }\end{array}$ & $\beta$ & $b$ & $t$ & \multicolumn{2}{|c|}{$\begin{array}{c}\text { The model's } \\
\text { statistical parameters }\end{array}$} \\
\hline \multicolumn{6}{|c|}{ Higher education (Bachelor's Degree) } \\
\hline Regression free member rating & & 0,561 & 1,11 & $\mathrm{R}$ & 0,613 \\
\hline Mediation-immediacy & 0,146 & 0,047 & 3,04 & $\mathrm{R}^{2}$ & 0,375 \\
\hline Autonomy & 0,189 & 0,036 & 2,04 & $\mathrm{~F}$ & 6,464 \\
\hline Self-expression & 0,207 & $-0,042$ & $-2,50$ & $\mathrm{p}$ & 0,001 \\
\hline \multicolumn{6}{|l|}{ Higher education (Master's Degree) } \\
\hline Regression free member rating & & 0,978 & 1,97 & $\mathrm{R}$ & 0,757 \\
\hline Creativity-mediocrity & 0,489 & 0,024 & 3,32 & $\mathrm{R}^{2}$ & 0,573 \\
\hline Autonomy-dependency & $-0,434$ & $-0,029$ & $-3,01$ & $\mathrm{~F}$ & 7,658 \\
\hline Integrity- non-integrability & 0,329 & 0,027 & 2,67 & \multirow[b]{2}{*}{$\mathrm{p}$} & \multirow{2}{*}{0,001} \\
\hline Self-development & $-0,467$ & $-0,111$ & $-4,37$ & & \\
\hline
\end{tabular}

Note. The level of significance of all model components $\mathrm{p}<0,01$. Accepted designations: $\beta-$ standardized regression coefficients; $b$ - estimation of model parameters; $t$ - Student's test value; $\mathrm{R}-$ regression coefficient; $\mathrm{R}^{2}$ - determination coefficient; $\mathrm{F}$ - F-test value; $\mathrm{p}$ - F-test level of significance.

Quality comparison of the regression analysis results shows pronounced dynamics in the subjective determination of student youths' social activity development - it gets higher as their level of education grows. For students receiving vocational education social activity has no subject determination and is probably determined by the activity connected with it. In the system of higher education, bachelor's students activity is determined by their desire to use the laws of the structure and functioning of the society for effective achievement of their goals (mediation) and depends on the ability to make their own vital decisions (autonomy). Prominent orientation to build their life according to their own values and desires (self-expression) can lower the manifestation of their social activity. Master's students have more predictors characterizing the level characteristics of personal subjective 
development. In terms of increasing their social activity such prominent personal subjective characteristics as openness to new experience and creation (creativity), the desire to integrate into the society on the basis of equal interaction with others and preserving their originality (integrity) show the great prognostic importance. Simultaneously expressed focus on self-development and independence in achieving life goals (autonomy) can determine the decline of social activity among students belonging to this group.

\section{Conclusion}

The study that has been carried out shows that student youth's social activity manifests itself mostly in leisure, virtual, and educational spheres of life. Wherein the higher the level of their education is, the more active there are in the activity connected with education development, and the less - in protest forms of activity. Generally, college and bachelor's students' activity is higher than that of master's students; this trend is especially visible in terms of civil and altruistic activity. Bachelor's students are also active in the activity connected with personal spiritual development.

The results of the study also allowed us to reveal the tendency in subject determination of student youth's social activity development - the higher the level of education received by them is, the more subjective characteristics act as predictors having the great predicting importance.

The study was funded by the grant of the Russian Scientific Fund (project № 18-18-00298).

\section{References}

1. D.V. Krotov, Social capital of Russian youth (YuFU Publ., Rostov-na-Donu, 2009)

2. E.S. Sokolova, Knowledge. Understanding. Skill, 1, 197-202 (2011)

3. S.P. Ivanenkov, A.V. Kostrikin, Credo new, 3, 82-100 (2009)

4. P. Moss, G. Moss, Child development perspectives, 2(2), 114-119 (2008)

5. K. Jeznik, Studies in Adult Education and Learning, 22(2), 39-52 (2016) DOI: https://doi.org/10.4312/as.22.2.39-52

6. B. A. Nazarova, B. H. Rakhimov, Problems of modern education, 1, 46-50 (2016).

7. R. M. Shamionov, A. V. Grigoryev, IJCRSEE, 7(1), 15-20 (2019) DOI: https://doi.org/10.5937/ijcrsee1901015S

8. R. Tallon, A. Milligan, B. Wood, Policy \& Practice: A Development Education Revie, 22, 96-109 (2016)

9. E. E. Bocharova, Izv. Saratov Univ. (N. S.), Ser. Educational Acmeology. Developmental Psychology, 7(4), 333-345 (2018) DOI: https://doi.org/10.18500/23049790-2018-7-4-333-345

10. E.N. Volkova, Psychology of teacher's subjectivity (Nizhny Novgorod Humanitarian Center Publ., Nizhny Novgorod, 2001)

11. M. A. Shchukina Psychology of personal self-development (SPbU Publ., St. Petersburg, 2015)

12. S.A. Bogomaz, S.A. Litvinova, Questionnaire methods of environmental identity research. Methodical guide (TGU Publ., Tomsk, 2015)

13. I.V. Arendachiuk, RUDN Journal of Psychology and Pedagogics, 15(3), 287-307 (2018) DOI: http://dx.doi.org/10.22363/2313-1683-2018-15-3-287-307 